\title{
Loss of Tsc1/Tsc2 activates mTOR and disrupts PI3K-Akt signaling through downregulation of PDGFR
}

\author{
Hongbing Zhang, ${ }^{1}$ Gregor Cicchetti, ${ }^{1}$ Hiroaki Onda, ${ }^{1}$ Henry B. Koon, ${ }^{2}$ Kirsten Asrican, ${ }^{1}$ \\ Natalia Bajraszewski, ${ }^{1}$ Francisca Vazquez, ${ }^{3}$ Christopher L. Carpenter, ${ }^{2}$ \\ and David J. Kwiatkowski ${ }^{1}$ \\ ${ }^{1}$ Department of Medicine, Brigham and Women's Hospital, \\ ${ }^{2}$ Beth Israel Deaconess Medical Center, and \\ ${ }^{3}$ Department of Medical Oncology, Dana Farber Cancer Institute, Harvard Medical School, Boston, Massachusetts, USA
}

\begin{abstract}
Tuberous sclerosis (TSC) is a familial tumor syndrome due to mutations in TSC1 or TSC2, in which progression to malignancy is rare. Primary $T s c 2^{-/-}$murine embryo fibroblast cultures display early senescence with overexpression of $\mathrm{P} 21^{\mathrm{CIP} 1 / \mathrm{WAF} 1}$ that is rescued by loss of TP53. Tsc2-/-TP53-/- cells, as well as tumors from $T s 2^{+/-}$mice, display an mTOR-activation signature with constitutive activation of $56 \mathrm{~K}$, which is reverted by treatment with rapamycin. Rapamycin also reverts a growth advantage of $T s c 2^{-/-} \mathrm{TP}^{-/ /}$cells. Tsc1/Tsc2 does not bind directly to mTOR, however, nor does it directly influence mTOR kinase activity or cellular phosphatase activity. There is a marked reduction in Akt activation in $T s c 2^{-/-} \mathrm{TP}^{-/-}$and $T s c 1^{-/-}$cells in response to serum and PDGF, along with a reduction in cell ruffling. PDGFR $\alpha$ and PDGFR $\beta$ expression is markedly reduced in both the cell lines and Tsc mouse renal cystadenomas, and ectopic expression of PDGFR $\beta$ in Tsc2-null cells restores Akt phosphorylation in response to serum, PDGF, EGF, and insulin. This activation of mTOR along with downregulation of PDGFR PI3K-Akt signaling in cells lacking Tsc1 or Tsc2 may explain why these genes are rarely involved in human cancer. This is in contrast to PTEN, which is a negative upstream regulator of this pathway.
\end{abstract}

J. Clin. Invest. 112:1223-1233 (2003). doi:10.1172/JCI200317222.

\section{Introduction}

Tuberous sclerosis (TSC) is an autosomal dominant tumor suppressor gene syndrome due to inactivating mutations in either of two genes, TSC1 and TSC2 (1-3). The tumors that occur in TSC are distinctive in that they typically consist of multiple cell types and replicate normal structures, and they are termed hamartomas. Cancer development is rare in TSC, occurring only in the kidney to an appreciable extent, where it is seen in $2-3 \%$ of all patients (2).

Null alleles of both $T s c 1$ and $T s c 2$ have been generated in the mouse (4-7). Heterozygotes for either gene develop multiple renal cystadenomas that progress at low frequency to renal carcinoma. Liver hemangioma are also seen in about half of heterozygous mice, are the most common cause of death in mice less than 18 months of age, and are more severe in females (5).

Received for publication October 23, 2002, and accepted in revised form August 17, 2003.

Address correspondence to: David J. Kwiatkowski, Genetics Laboratory, Hematology Division, 221 Longwood Avenue, LM-302, Boston, Massachusetts 02115, USA.

Phone: (617) 278-0384; Fax: (617) 734-2248;

E-mail: dk@rics.bwh.harvard.edu.

Conflict of interest: The authors have declared that no conflict of interest exists.

Nonstandard abbreviations used: tuberous sclerosis (TSC); murine embryo fibroblast (MEF); passage eight (P8); Earle's balanced salt solution (EBSS); Nonidet P-40 (NP-40); PH domain of Akt fused to YFP (YPH-Akt); yellow fluorescent protein (YFP); phosphatidic acid (PA).
Null embryos for either gene die at midgestation of apparent failure of liver development $(4,5)$.

Recent genetic screens in Drosophila have revealed a critical role for the orthologues of these genes, $T s c 1$ and $T s c 2$, in the control of cell growth and organ size (8-10). Homozygous inactivation of either Tsc1 or Tsc2 leads to an identical phenotype in which organogenesis and differentiation proceed fairly normally, but there is an increase in the size of the overall organ that is nearly entirely due to an increase in cell size. Comparison with phenotypes produced by other knockouts and epistasis analysis suggested that $T s c 1$ and $T s c 2$ interacted with the insulin receptor PI3K-Akt-S6k-signaling pathway, although other possibilities were also suggested (8-10).

We then showed in cultured murine cells lacking Tsc1 that there is constitutive high-level phosphorylation of S6K and 4E-BP1, which is rapidly reversed by treatment with rapamycin, identifying $\mathrm{mTOR}$ as a negative target of Tsc1 (5). Subsequent work in Drosophila also indicated that Tsc1 and Tsc2 acted in this pathway somewhere near mTOR $(11,12)$. In addition, both in Drosophila and mammals, tuberin (product of the $T s c 2$ gene) is phosphorylated by activated Akt, and this activation serves to accelerate the dissolution and/or degradation of the tuberin-hamartin (hamartin is the product of the Tsc1 gene) complex (12-15).

Here we present the derivation and analysis of a series of Tsc2-null MEF lines and provide evidence that tuberin and hamartin together have a critical function in mammalian cells in the regulation of mTOR activity. Fur- 
thermore, we show that there is an abnormality of PI3KAkt signaling in response to growth factor stimulation due to reduced expression of PDGFR $\alpha$ and PDGFR $\beta$ in cells lacking Tsc2. Similar findings are also seen in Tsc1null cells and tumors from $T s c 1^{+-}$and $T s c 2^{+/-}$mice.

\section{Methods}

Animal care and breeding. Mice were maintained under supervised humane conditions as described (4). Mice bearing the TP53- allele were provided by P. Leder (Harvard Medical School, Boston, Massachusetts, USA), with the consent of L. Donehower (Baylor College of Medicine, Houston, Texas, USA) (16). Genotyping was performed as described (4).

Murine embryo fibroblast culture. Embryonic day (E) 10-12.5 embryos were collected from $\mathrm{Tsc}^{+/-}$or $T s c 2^{+/-} \mathrm{TP}^{-1 /-}$ intercrosses, triturated in DMEM, and plated in DMEM with $10 \% \mathrm{FCS}$ in $5 \% \mathrm{CO}_{2}$. Serum deprivation was done for 1-3 days and restimulation for 10-60 minutes. Whenever possible, experiments were performed on the $\mathrm{TP}^{-3^{--}}$cell lines prior to passage eight (P8). There was no significant difference in the characteristics of these lines in early (less than P9) compared with late passage (P10 and higher) cells, however.

The human TSC2 full-length cDNA was subcloned into pEF6 (Invitrogen Corp., Carlsbad, California, USA). TP53 $3^{-/} T s c 2^{-/-}$murine embryo fibroblasts (MEFs) were transfected with pEF6/TSC2 and selected with blasticidin.

Reagents and $A b$ 's. Reagents were obtained from the following sources: LY294002, rapamycin, PD98059, and MAP kinase were from Cell Signalling Technology (Beverly, Massachusetts, USA); BrdU, PDGF-BB, and EGF were from Sigma-Aldrich (St. Louis, Missouri, USA); wortmannin, TPCK, and U0126 were from Biomol Research Laboratories (Plymouth Meeting, Pennsylvania, USA); 1-butanol and 2-butanol were from EM Science (Gibbstown, New Jersey, USA); Earle's balanced salt solution (EBSS) and MEM amino acids were from Invitrogen Corp.; HBSS was from Mediatech (Herndon, Virginia, USA); and rat 4E-BP1, AG17, and insulin were from Calbiochem Corp. (San Diego, California, USA).

An anti-hamartin $\mathrm{Ab}, \mathrm{H} 2$, was generated in the rabbit using the peptide CDGMTSSLSESLKTELGKDLGVEAK (human hamartin residues 1107-1130) conjugated to KLH. Another Ab against the C-terminal 204 residues of hamartin has been described (5). Other Ab's were obtained as follows: $16^{\mathrm{INK} 4 \mathrm{a}}, \mathrm{p} 27^{\mathrm{KIP} 1}, \mathrm{p} 21^{\mathrm{CIP} 1 / \mathrm{WAF} 1}$, TSC2 C20, TSC2 N19, 14-3-3, Akt, ERK, S6K, PDGFR $\alpha$, PDGFR $\beta$, EGFR, PI3K-p85, and insulin receptor- $\alpha$ were from Santa Cruz Biotechnology Inc. (Santa Cruz, California, USA); pAkt (Ser473), pS6K (Thr389), pS6K (Thr421/Ser424), pS6 (Ser235/236), pS6 (Ser240/244), pp90RSK (T359/S363), pERK, and eIF4E were from Cell Signalling Technology; phosphotyrosine (ptyr, 4g10) was from Upstate Biotechnology Inc. (Lake Placid, New York, USA); and mTOR was from BD Biosciences (Palo Alto, California, USA).

Protein analyses. Immunoblot analyses were performed as described (5). Immunoprecipitation was performed after protein extraction in lysis buffer $(150 \mathrm{mM} \mathrm{NaCl}$, $1 \mathrm{mM}$ EDTA, $50 \mathrm{mM}$ Tris, $\mathrm{pH}$ 7.4, $1 \%$ Nonidet P-40 [NP-40], $1 \mathrm{mM} \mathrm{PMSF,} 1 \mathrm{mM} \mathrm{Na}_{3} \mathrm{VO}_{4}$, Roche protease inhibitor cocktail; Roche Diagnostics, Basel, Switzerland) and determination of protein concentration by the Bradford assay, using Ab's and protein A or $\mathrm{G}$ beads.

Purification of Tsc1/Tsc2. Extracts were prepared from mouse brain by homogenization in extraction buffer (50 mM Tris, pH 8, $5 \mathrm{mM}$ mg acetate, $1 \mathrm{mM}$ EDTA, 1 mM DTT, 1 mM PMSF, 10\% glycerol, Roche protease inhibitor cocktail). Serial immunoaffinity purification was performed using anti-hamartin Ab H2 elution with peptide and then repeated with antituberin $\mathrm{Ab}, \mathrm{C} 20$ or N19.

Kinase and phosphatase assays. To assay mTOR kinase activity, mTOR was immunoprecipitated from mouse brain extracts in $0.1 \%$ Tween 20 with Ab's and protein G. Mixtures of mTOR, Tsc1/Tsc2, and rat 4E-BP1 were incubated in kinase buffer with $200 \mu \mathrm{M}$ ATP and $5 \mu \mathrm{Ci} \gamma^{32} \mathrm{P}$-ATP at $30^{\circ} \mathrm{C}$ for 30 minutes. Dried SDSPAGE gels were exposed to Kodak Biomax film (Rochester, New York, USA).

Phosphatase assays were performed using bacterially expressed 4E-BP1-GST (plasmid was the gift of J. Avruch, Massachusetts General Hospital, Boston, Massachusetts, USA) (17). Purified 4E-BP1-GST was labeled with MAP kinase and $\gamma^{32}$ P-ATP. Labeled 4E-BP1-GST on beads was washed with phosphatase buffer $(50 \mathrm{mM}$ Tris, pH 8, $0.5 \mathrm{M} \mathrm{NaCl}, 1 \% \mathrm{NP}-40,1 \mathrm{mM}$ PMSF, Roche protease inhibitor cocktail), and $12-\mu$ l beads were incubated with $50 \mu \mathrm{l}$ cell lysates in phosphatase buffer for 20 and 40 minutes at $25^{\circ} \mathrm{C}$.

PI3K assays were done as described previously (18). Briefly, cells were lysed in TNE (50 mM Tris-HCl, $\mathrm{pH}$ $7.5,150 \mathrm{mM} \mathrm{NaCl}$, and $1 \mathrm{mM}$ EDTA), $1 \%$ NP-40 with Roche protease inhibitor cocktail. Lysates containing equal amounts of protein were immunoprecipitated with anti-PDGFR $\beta$ or anti-ptyr $\mathrm{Ab}$ and protein $\mathrm{G}$ for 2 hours at $4^{\circ} \mathrm{C}$ with constant rocking. The beads were washed, and lipid kinase assays were performed by addition of PtdIns, PtdIns-4-P, PtdIns-4,5-P, and $\gamma^{32}$ P-ATP. Lipids were then extracted and separated by thin-layer chromatography using 1-butanol and $2 \mathrm{M}$ acetic acid. Standards were visualized by iodine staining, and the reaction products were visualized by autoradiography.

Translocation of the PH-domain of Akt and ruffling assay. Cells were serum starved for 16 hours and microinjected with an expression vector encoding the $\mathrm{PH}$-domain of murine Akt tagged with a yellow variant of the GFP (YPH-Akt, the PH domain of Akt, was kindly provided by Tobias Meyer, Stanford University, Stanford, California, USA). Cells were studied 3 to 4 hours after microinjection. In other experiments, $T s c 2^{-/-}$cells were cotransfected at a 1:1 ratio with PcDNA3.1/GS/PDGFR and the YPH-Akt expression vector using Lipofectamine 2000 (Invitrogen Corp.). Four hours after transfection, the cells were serum starved overnight. Cells were stimulated with $20 \mathrm{ng} / \mathrm{ml}$ PDGF, and videomicroscopy was performed using an inverted epifluorescence microscope 
(Diaphot 300; Nikon Corp. Imaging Co., Tokyo, Japan) with a $\times 40$ Nikon plan objective lens and equipped with a cooled charge-coupled device camera (CCD-1300-Y; Roper Scientific, Duluth, Georgia, USA). Yellow fluorescent protein (YFP) was excited using a $500-\mathrm{nm}( \pm 15 \mathrm{~nm})$ bandpass filter, and YFP emission was recorded using a $535 \mathrm{~nm}( \pm 15 \mathrm{~nm})$ bandpass filter. During imaging, cells were kept at $37^{\circ} \mathrm{C}$. Ruffling activity of cells was assessed in similarly treated cells by phase-contrast microscopy using a $\times 10$ Nikon plan objective. The number of cells displaying dorsal ruffles within 20 minutes after stimulation with PDGF was counted in a blinded manner.

BrdU incorporation, metabolic labeling. Cells were grown to $90 \%$ confluence and serum starved for 1 day or 3 days. Serum-free media containing $10 \mu \mathrm{M}$ BrdU with or without $50 \mathrm{ng} / \mathrm{ml} \mathrm{EGF}$, or $25 \mathrm{ng} / \mathrm{ml}$ PDGF-BB, or 25 $\mu \mathrm{M}$ AG17 were added, and the cells were incubated for 16 hours. Cells were then fixed in 3.7\% formaldehyde and permeabilized using $0.5 \%$ Triton X-100. The DNA was denatured using $4 \mathrm{M} \mathrm{HCl}$, and cells were then immunostained using a monoclonal $\mathrm{BrdU} \mathrm{Ab}$ and a rhodamine-labeled goat anti-mouse Ab. Phase images were taken to determine the total number of cells, and fluorescence images were used to determine the number of BrdU-positive cells. Similar experiments were performed with cell counting.

For metabolic labeling, cells were cultured in methionine-free DMEM plus $0.14 \mathrm{mCi} / \mathrm{ml}^{35} \mathrm{~S}$-methionine for 30 minutes, followed by addition of regular serum-free DMEM. Cells were then harvested at 0, 45-minute, 90minute, 120 -minute, and 180-minute time points during the chase. PDGFR $\beta$ was then immunoprecipitated from the cell extracts in immunoprecipitation lysis buffer, as above. The immunopurified proteins were separated by SDS/PAGE and dried for autoradiography.

Mass-spectrometry analysis of proteins. Purified proteins were separated by SDS/PAGE and stained with GelCode Blue Stain Reagent (Pierce Chemical Co., Rockford, Illinois, USA). Protein bands were then excised and analyzed at the Harvard Microchemistry Facility (Harvard University, Cambridge, Massachusetts, USA) by microcapillary reverse-phase HPLC nanoelectrospray tandem mass spectrometry on a ThermoQuest Finnigan LCQDeca Quadrupole Ion Trap Mass Spectrometer.

\section{Results}

Tsc2-null fibroblasts display early senescence. To investigate the growth characteristics of cells lacking Tsc2, we prepared cultures of early-stage mouse embryos derived from $T s 2^{+/-}$interbreedings. MEF cultures were established by standard methods from viable E10.5-11.5 $T s c 2^{-/}$embryos and their littermates. Tsc2-/- MEF cultures uniformly displayed more limited growth in culture than $T s c 2^{+/-}$or $T s c 2^{+/+}$MEFs, failing to divide after P8 (Figure 1a). In contrast, $T s c 2^{+/-}$and $T s c 2^{+/+}$MEFs continued to expand past P10 in all cases, with growth plateauing after about ten divisions in most cases. Both types of cell lines gave rise spontaneously to immortalized, rapidly growing derivative cell lines between P10 and P25 (Figure 1a). For the $T s c 2^{+/-}$and $T s c 2^{+/+}$cultures, this occurred in all cases $(n=5)$. For $T s c 2^{-/-}$cultures, however, this occurred in one of five cases.

Phase-contrast views of $T s c 2^{-/-}$cells at P8 to P12 demonstrate that they have features that are indicative of senescence (Figure 1b). Cells are large with relatively large processes, and they fail to incorporate BrdU, indicating cell-cycle arrest. FACS analysis of cell-cycle distribution at P10 showed that they had normal DNA content and were $81 \%$ G1 and $19 \%$ G2 plus M phase, compared with $49 \% \mathrm{G} 1,3 \% \mathrm{~S}$, and $48 \% \mathrm{G} 2$ plus $\mathrm{M}$ distribution for $\mathrm{Tsc2}^{+/+}$MEFs at identical passage. Immunoblot analysis of cell lysates demonstrated that the Tsc2 $2^{-/-}$MEFs had elevated levels of the cdk inhibitor $\mathrm{p} 21^{\mathrm{CIP} 1 / \mathrm{WAF} 1}$ compared with $T s c 2^{+/-}$and $T s c 2^{+/+} \mathrm{MEFs}$ of identical passage (Figure 1c). In contrast, levels of the p2 $7^{\mathrm{KIP} 1} \mathrm{cdk}$ inhibitor, previously implicated in growthsignaling abnormalities in Tsc2-null rat embryo fibroblasts (19), as well as the cdk inhibitor $\mathrm{p} 16^{\mathrm{INK} 4 \mathrm{a}}$, were no different among the different types of MEFs.

Rescue of $T s c 2^{-/-}$induced senescence by $p 53$ loss. To circumvent the premature senescence of $T s c 2^{-/}$MEFS, mice bearing the $T s c 2^{-}$allele were interbred with mice carrying a null allele for TP53 to obtain $T P 53^{-/-} \mathrm{Ts} 2^{+/-}$ mice. Breeding studies showed that being null for TP53 did not improve the survival of Tsc2 $2^{-/}$embryos, because none survived past E12.5 and double-null embryos at E10.5 often were more poorly developed than littermates that were also $T P 53^{-/-}$but $T s 2^{+/-}$or $T s c 2^{+/+}$. Viable E10.5 TP53 $3^{-/-} T s c 2^{-/-}$embryos gave rise to MEF cultures that grew rapidly and indefinitely without senescence (five of five embryos), similar to $T P 53^{-/-} \mathrm{Tsc} 2^{+/-}$(four of four) and TP53 ${ }^{-/-} \mathrm{Tsc}^{+/+}$(three of three) cultures derived from littermates.

There were no significant differences in growth rates in $10 \%$ serum among these cell lines (see below; Figure 3b, top). In short-term growth experiments in the absence of serum, however, TP53-- Tsc2 $2^{--}$MEFs displayed continuing growth in contrast to control TP53 $3^{--}$MEFs (Figure $3 \mathrm{~b}$, bottom). The $\mathrm{p} 21^{\mathrm{CIP} 1 / \mathrm{WAF} 1}$ levels were undetectable in extracts from these MEFs (data not shown), while levels of $\mathrm{p} 27^{\mathrm{KIP} 1}$ and $\mathrm{p} 16^{\mathrm{INK} 4 \mathrm{a}}$ were equivalent (Figure $1 \mathrm{~d}$ ).

Expression of tuberin and hamartin was examined in these $T P 53^{-/-} \mathrm{TsC}^{-/-}$cell lines and compared with $T s c 1^{-/-}$ cell lines described previously (5). Tuberin levels were reduced by over half in $\mathrm{Tsc}^{-/-}$cell lines compared with controls, while hamartin levels were not affected by loss of tuberin (Figure 1e). In addition, there was no change in tuberin or hamartin levels, or their physical association in control MEF cells in response to PDGF or serum stimulation (Figure 1f).

Growth-signaling alterations in $\mathrm{Tsc} 2^{--}-\mathrm{TP} 53^{-/-}$cells. The growth advantage that we detected in the absence of serum suggested that growth stimulatory pathways might be constitutively active in Tsc2-null cells. This idea was supported by our previous studies indicating that 4E-BP1, S6K, and S6 were constitutively phosphorylated and activated in Tsc1-null cells (5). Therefore, we examined several signaling pathways relevant for control 
a

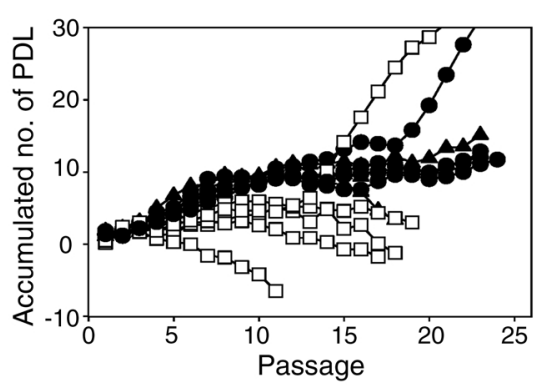

c

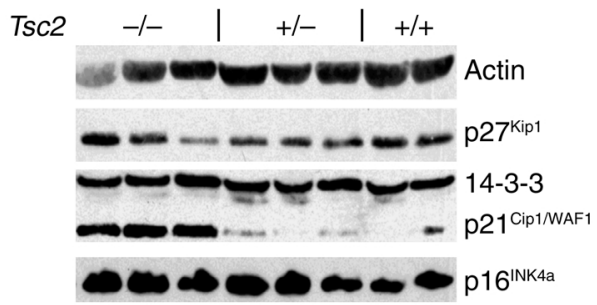

e

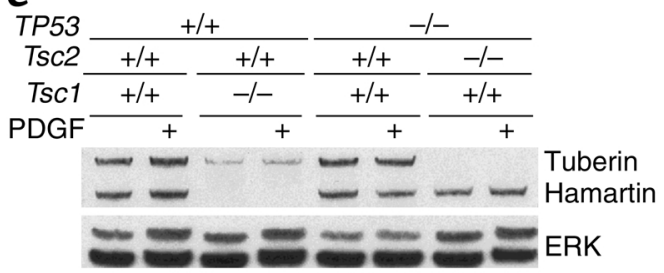

b

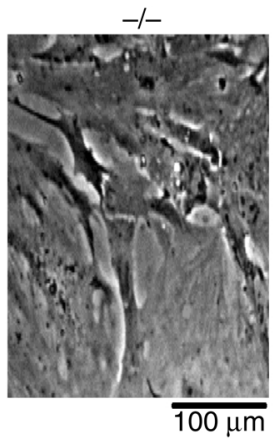

d $\mathrm{p} 53$ TsC2
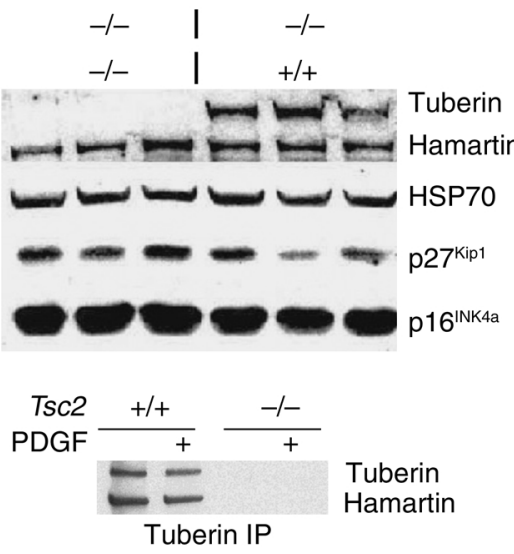

Figure 1

Premature senescence of $T s c 2^{-/-} \mathrm{MEF}$ cultures. (a) Growth curves of cultured $T s c 2^{-/-}$(open squares), $T s c 2^{+/-}$ (filled circles), and wild-type (filled triangles) MEFs. PDL, population doubling. (b) Phase-contrast view of senescent P8 Tsc2-/- (left) and P8 control (right) MEFs. (c) Immunoblot analysis of extracts from primary MEF cultures of the indicated genotypes. Note the increased expression of $\mathrm{p} 21^{\mathrm{CIP} 1 / \mathrm{WAF} 1}$ by the Tsc2 ${ }^{-/-}$MEFs. (d) Immunoblot analysis similar to that shown in $c$ of TP53-1- MEF lines with various Tsc2 genotypes. (e) Left, immunoblot analysis of tuberin, hamartin, and ERK expression by MEFs with various genotypes. Note reduced expression of tuberin in the Tsc1-null MEFs. Right, tuberin immunoprecipitation (IP) from starved and stimulated (30 minutes) TP53 ${ }^{-/-}$cells shows no change in tuberin or hamartin expression levels or association. of cell growth, using the TP53-/- MEF lines in serumstarved cultures with or without serum refeeding (Figure 2a). Expression of ERK isoforms was similar in these MEFs irrespective of genotype. In comparison with control cells, two TP53 ${ }^{-/-}$Tsc $2^{-/-}$MEF lines showed a reduction in the level of activated ERK1 and ERK2 in response to serum stimulation (Figure $2 \mathrm{a}$, first and seventh pair of lanes), but this was not seen in all TP53-/-Tsc2 $2^{-/-}$MEFs (Figure $2 \mathrm{a}$, third and fourth pair of lanes). Activation of p90 RSK by serum was similar in all of these cell lines. In contrast, activation of Akt in response to serum was markedly reduced in all of the $T P 53^{-/-} T s c 2^{-/-}$cells, as assessed by phosphorylation at Ser473. Moreover, S6K was constitutively activated in all of the Tsc2-null cells in the absence of serum, as assessed by phosphorylation at Thr389, and showed only a modest increase in phosphorylation with serum stimulation (Figure 2a). Consistent with constitutive activation of S6K, pS6 levels (Ser235/236) were also increased in the $T P 53^{-/-} \mathrm{Tsc}^{-/-}$ cells in the absence of serum and did not increase with serum refeeding (Figure $2 \mathrm{a}$ ). In these experiments we examined several TP53 $3^{-/-} \mathrm{Tsc} 2^{+/+}$and $\mathrm{TP53} 3^{-/-} \mathrm{Tsc} 2^{+/-} \mathrm{MEF}$ lines and saw no difference between them, indicating that haploinsufficiency for Tsc2 had no effect on these pathways (Figure 2a).

We also examined the state of activation of this pathway in tumors derived from $T s c 2^{+/-}$mice, which are known to show loss of heterozygosity for the wild-type
Tsc2 allele in most cases (4). ERK and eIF4E levels were similar, while pS6 was present only in cystadenomas and not in control kidney tissue of these mice (Figure 2b). We also generated a revertant, TSC2-expressing stably transfected cell line from a $\mathrm{TP} 53^{-/-} \mathrm{Tsc} 2^{-/-}$cell line. In the revertant cell line, expression of pS6K and pS6 under conditions of serum starvation was markedly reduced, similar to TP53-/- control cell lines (Figure 2c).

In summary, we have shown that there is constitutive high-level activation of S6K in the Tsc2-null TP53-/- cell lines as well as Tsc2-null tumors from $T s c 2^{+/-}$mice. In contrast, Akt activation is markedly reduced in response to growth factor stimulation in Tsc2-null lines. These findings were entirely similar in both earlypassage (P5) and late-passage (greater than P20) Tsc2null TP53-/- cell lines (data not shown).

Inhibitors of $m$ TOR specifically revert the $S 6 K$ activation and growth phenotype of TP53-/-Tsc2 $2^{-/}$cells. These findings, as well as previous observations $(5,11,20)$, implicated an abnormality in signaling at approximately the level of $\mathrm{mTOR}$ in cells lacking Tsc2. To explore this defect, we examined the effects of treatment with several inhibitors of the kinases in this pathway (Figure 3a). In serumstarved TP53-/-Tsc2 $2^{-/-}$cells, treatment with either $10 \mathrm{nM}$ rapamycin or $10 \mu \mathrm{M}$ LY294002 abolished the phosphorylation of 56 , consistent with their actions in inhibiting mTOR $(21,22)$. Wortmannin $(0.1 \mu \mathrm{M})$ (inhibits PI3K; ref. 23), however, had no effect on phosphorylation of S6 in 
the serum-starved $T P 53^{-/-} T s c 2^{-/-}$cells. Treatment of the Tsc2-null cells with three additional inhibitors, TPCK (inhibits PDK1; ref. 24), U0126 (inhibits MEK kinase; ref. 25), and PD98059 (inhibits MAPKK; ref. 26), also failed to have significant effects on the levels of pS6, while calyculin A (serine-threonine phosphatase inhibitor; ref. 27) slightly increased S6 phosphorylation (Figure 3a). In aggregate, these observations suggest that the activation of S6K in Tsc2-null cells is dependent upon functional mTOR but independent of PI3K, PDK1, or MEK kinases (22-27). Analysis of control serum-stimulated TP53-/lines demonstrated that these compounds all had their predicted effects (Figure 3a, top).

We also assessed the importance of functional mTOR on the growth characteristics of the TP53-/-Tsc2 $2^{-/-}$cells. The persistent growth of the Tsc2-null cells in the absence of serum was reduced by rapamycin treatment in the range of $50 \mathrm{pM}$ to $50 \mathrm{nM}$ (Figure $3 \mathrm{~b}$ ). Even in 50 $\mathrm{nM}$ rapamycin, however, the growth behavior of the TP53-/-Tsc2 $2^{-/-}$lines was still distinct from that of Tsc2 wild-type $\mathrm{TP}^{-1-} 3^{--}$lines, perhaps reflecting short-term persistence of a growth advantage despite effective mTOR inhibition. Analysis of cell extracts from these cells under these conditions confirmed that the activation of S6K and S6 was abolished by rapamycin at doses from $50 \mathrm{pM}$ to $50 \mathrm{nM}$ (data not shown).

To explore the importance of other stimuli in the regulation of mTOR activity in Tsc2-null cells, we examined the effects of reduction in phosphatidic acid (PA) and AA levels $(28,29)$. Treatment with 1-butanol or 2-butanol to reduce cellular PA levels resulted in a reduction in pS6K levels in both serum-starved and serum-stimulated $\mathrm{TP53} 3^{-/} \mathrm{Tsc2^{-/ }}$ cells and had similar effects on serum-stimulated control TP53 ${ }^{-/}$cells (28) (Figure 3c). Exposure of previously serum-starved $\mathrm{TP53}^{-/-} \mathrm{Tsc} 2^{-/-}$cell lines to an absence of AA led to a significant reduction in pS6K and pS6 levels, while addition of fresh AA appeared to increase pS6K and pS6 levels to a small extent (Figure 3d).

Analysis of the tuberin-hamartin complex and potential interactors. Since these observations suggested a potential interaction between Tsc1/Tsc 2 and mTOR, we performed an in vitro kinase assay combining immunopurified mTOR, immunopurified Tsc1/Tsc2, $\gamma^{32} \mathrm{P}-\mathrm{ATP}$, and bacterially expressed 4E-BP1 (Figure 4a). Phosphorylation of both mTOR (autokinase

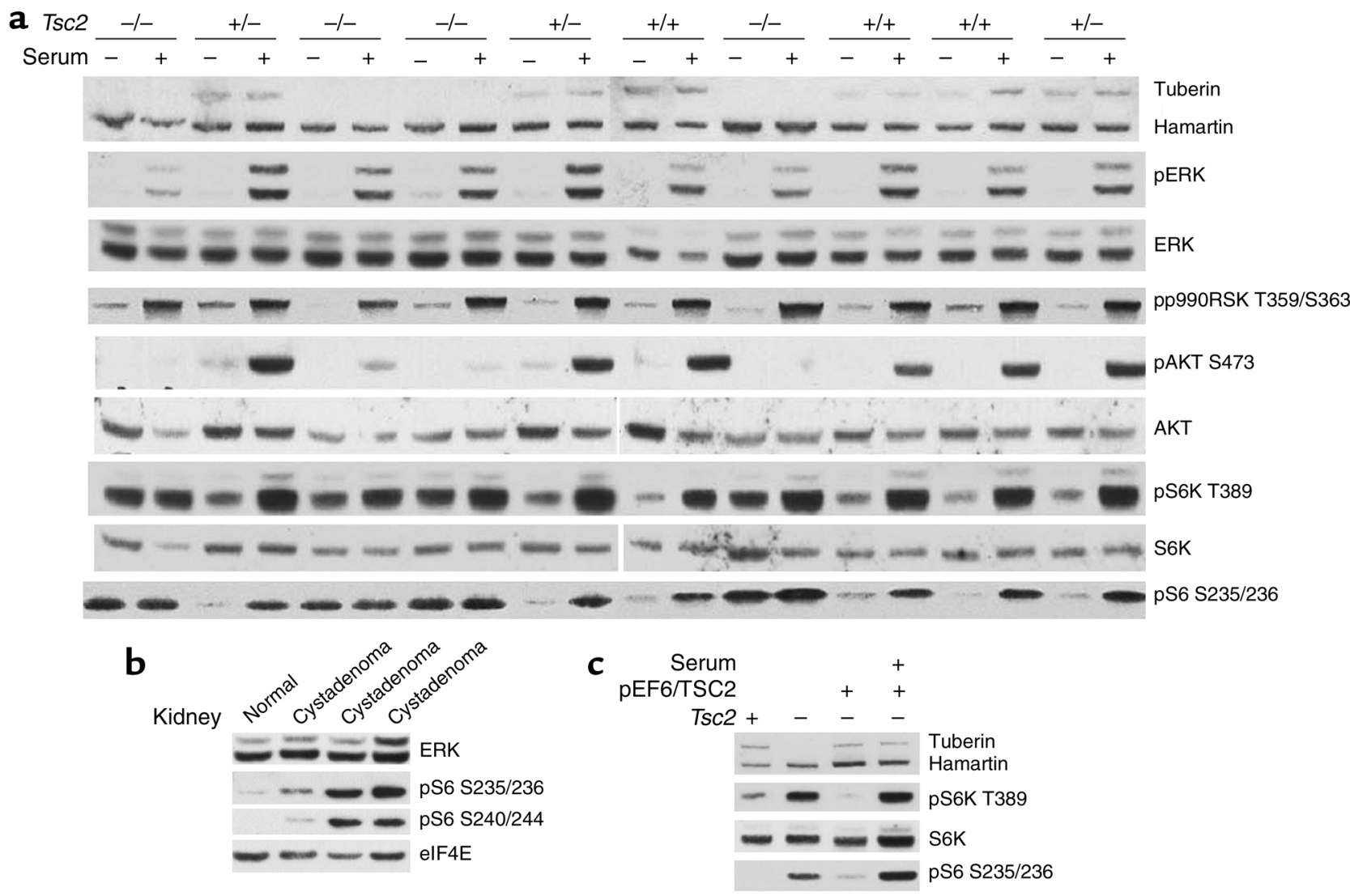

Figure 2

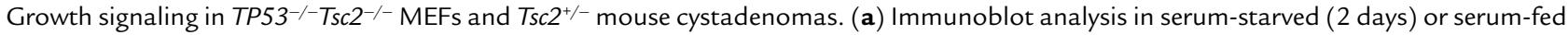
(30 minutes) TP53-/- MEFs. Genotypes are indicated across the top. Note that tuberin is not expressed in the Tsc2-/- cell lines; pAkt levels increase very little in the $T s c 2^{-/-}$cell lines in response to serum, and pS6K and pS6 levels are increased in the Tsc2 ${ }^{-/-}$cell lines without serum addition. (b) Immunoblot analysis on renal cystadenomas derived from $T s c 2^{+/-}$mice. Note the presence of pS6 in all three cystadenomas. (c) Immunoblot analysis of a revertant TP53 $3^{--}$Tsc2 ${ }^{-/-}$cell line expressing TSC2. Note the decrease in pS6K and pS6 levels in the revertant line during serum starvation. pS6 S235/236, pS6 (Ser235/236). 
$\mathbf{a}$

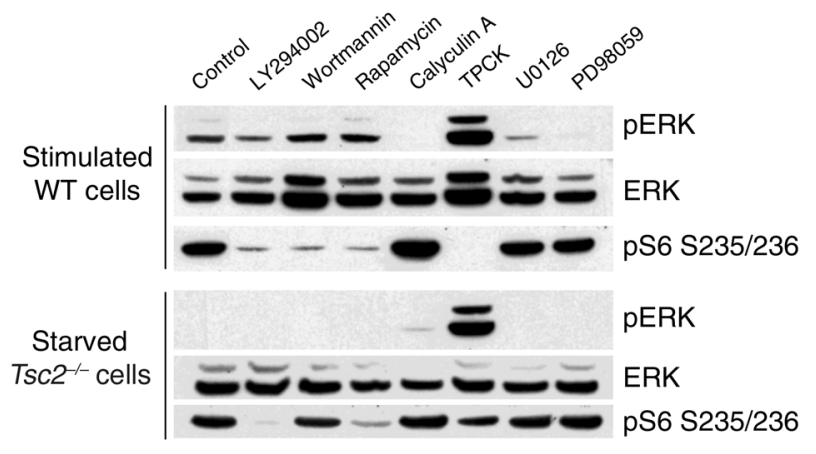

b
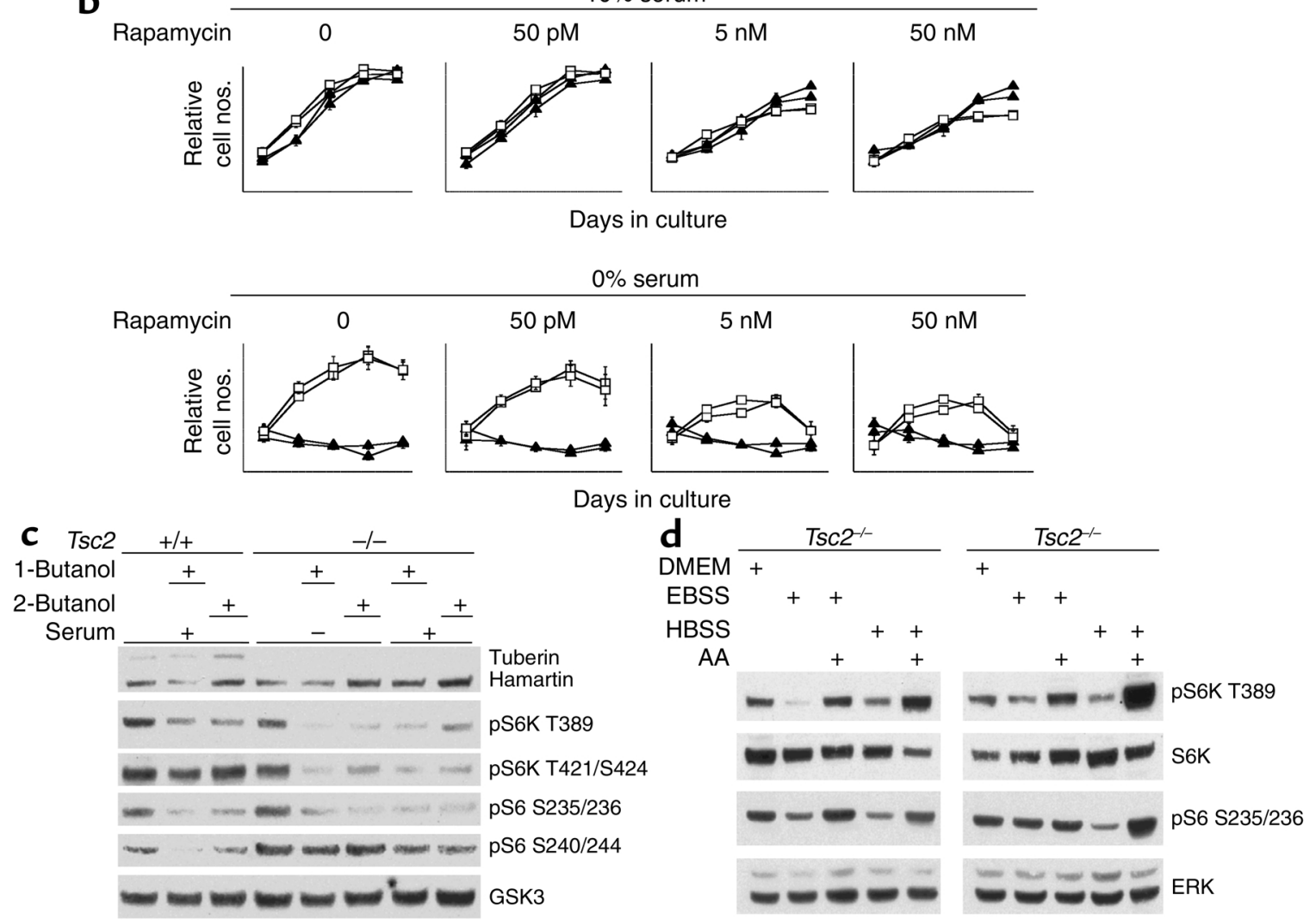

\section{Figure 3}

Effects of inhibitors on S6K/S6 phosphorylation and growth of TP53-/-Tsc2 ${ }^{-/-}$and control TP53-/- MEFs. (a) Immunoblot analysis of a

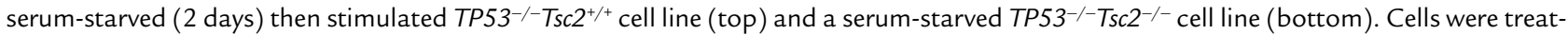
ed with $10 \mu \mathrm{M}$ LY294002, $0.1 \mu \mathrm{M}$ wortmannin, $10 \mathrm{nM}$ rapamycin, $0.1 \mu \mathrm{M}$ calyculin A, $5 \mu \mathrm{M}$ TPCK, $10 \mu \mathrm{M} \cup 0126$, or $20 \mu \mathrm{M}$ PD98059 for

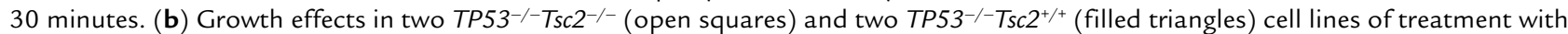
rapamycin. Each symbol reflects a consecutive day in culture. Rapamycin selectively reduces the growth of the TP53 $3^{-/-} T s c 2^{-/-}$cell lines in $0 \%$

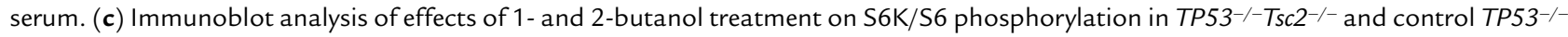
cell lines. 1 - or 2-butanol (0.3\%) were applied to the cell lines for 30 minutes, and the cells were serum stimulated for 5 minutes. (d) Immunoblot analysis of effects of AA deprivation and stimulation on S6K/S6 phosphorylation in two TP53 $3^{-/-}$Tsc2 $2^{-/-}$cell lines. All treatments were for 2 hours. Note that with either the EBSS or HBSS buffers, AAs are required to maintain pS6K and pS6 phosphorylation.

activity) and 4E-BP1 were seen under these conditions, but was not influenced by incubation with Tsc1/Tsc2. We also assessed the possibility that Tsc1/Tsc2 might influence phosphatase activity on mTOR kinase substrates. Labeled ${ }^{32} \mathrm{P}-4 \mathrm{E}-\mathrm{BP} 1$ was added to cell extracts from control or $T P 53^{-/-} T s c 2^{-/-}$ cells, and there was no difference in phosphatase activity among the different samples (Figure 4b).
To identify potential interactor(s) of Tsc1/Tsc2, we directly purified the Tsc1/Tsc2 complex from mouse brain by serial immunoaffinity chromatography (Figure 4c). A complex consisting of Tsc2 (tuberin) and Tsc1 (hamartin) could be purified (confirmed by mass spectrometry), demonstrating the highly stable binding between these proteins at approximately 1:1 stoichiometry. One band of size $30 \mathrm{kDa}$ was identified as being 
14-3-3 $\gamma$. This was confirmed by immunoblotting (Figure 4d). Several other fainter bands were seen in the purified material, all present at a stoichiometry of much less than 1:1. Akt and mTOR, previously described (11, 13) as occurring in association with Tsc1/Tsc2, were not present in this purified complex (Figure 4d).

Reduction in PI3K-Akt signaling in TP53 ${ }^{-/-} \mathrm{Tsc} 2^{-/-}$and Tsc1-/- cells. To understand the major reduction in serumstimulated activation of Akt in Tsc2-null cells (Figure 2a), we explored whether there was a change in kinetics rather than the extent of Akt activation. Activation of Akt (assessed by phosphorylation at Ser473) was markedly reduced in the Tsc2 $2^{--} T P 53^{--}$cells at all time points (10,30, 60, and 90 minutes) in comparison with control TP53 $3^{--}$cells, and the kinetics were no different from control cells (Figure 5a). A marked difference in the level of Akt activation in Tsc1- and Tsc2-null cells compared with control cells persisted after treatment with calyculin A (Figure $5 \mathrm{~b}$ ), suggesting that the difference was due to a lack of phosphorylation of Akt in both Tsc1- and Tsc2-null cells rather than differences in phosphatase activity. To explore this further, we assessed PI3K activity in these cells. Using both serum at 10\% (data not shown) and PDGF at $50 \mathrm{ng} / \mathrm{ml}$ stimulation, there was a significant reduction in the amount of $3^{\prime}$ phosphoinositides generated by phosphotyrosine or PDGFR $\beta$ immunoprecipitates from the $T s c 2^{-/-} \mathrm{TP} 53^{-/-}$ cells compared with TP53-/- control cells (Figure 5c).
As a measure of the response to PDGF stimulation, we also examined the degree of ruffling and of intracellular translocation of a reporter molecule for D3-polyphosphoinositide generation, consisting of the $\mathrm{PH}$ domain of Akt fused to YFP (YPH-Akt). The Tsc2-/-TP53-/- cells displayed reduced ruffling activity in response to stimulation with PDGF compared with control cell lines (Figure $5 \mathrm{~d})$. In addition, there was a marked reduction in the extent of translocation of the YPH-Akt reporter protein (Figure 5e). In control cells, translocation of the reporter to the cell surface in response to PDGF treatment resulted in a uniform staining appearance, while in the Tsc2-/-TP53-/- cells the YPH-Akt showed a generalized cytoplasmic location that did not change with PDGF treatment. The revertant cell line in which TSC2 expression was restored had a ruffling response and YPH-Akt translocation that was similar to the control Tsc2expressing $\mathrm{TP}^{-/-}$cell lines (Figure $5, \mathrm{~d}$ and e).

These results demonstrated that there was a major reduction in PI3K activity and Akt activation in cells lacking Tsc2 in response to both serum and PDGF. We then examined the possibility that differences in receptor amount or activation resulted in these differences in PI3K activation. Expression of PDGFR $\beta$ and

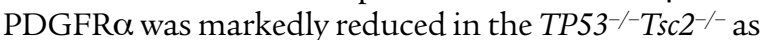
well as $T s c 1^{-/-}$cells in comparison to control cell lines (Figure 6a). In contrast, there was little or no difference in insulin receptor expression in these cell lines (Figure 6a).

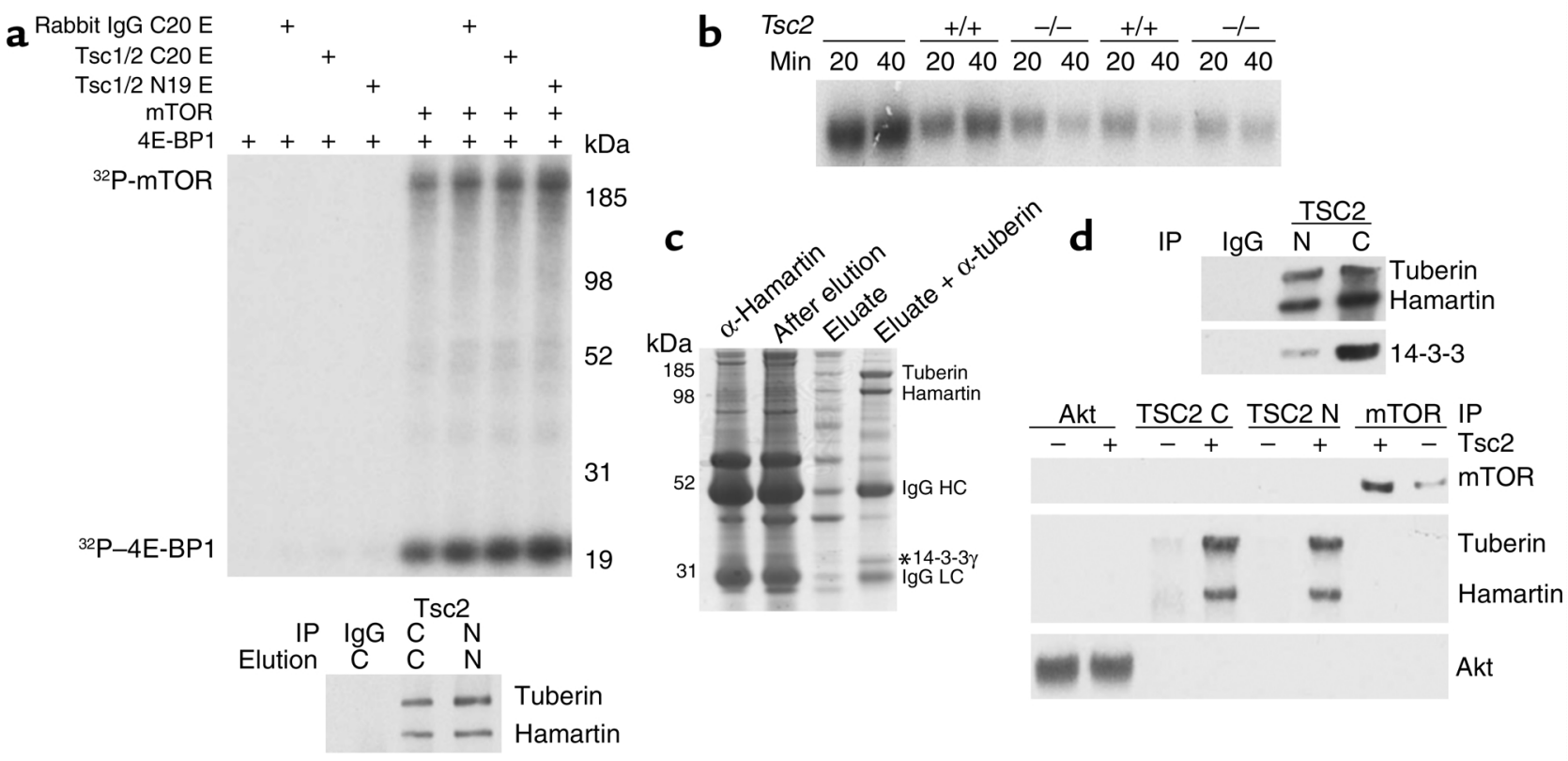

\section{Figure 4}

The mTOR functional analysis and purification of a Tsc1/Tsc2 complex. (a) Autoradiograph from an mTOR kinase reaction. Addition of mTOR and Tsc1/Tsc2 are indicated at the top. Equivalent amounts of mTOR autokinase activity and kinase activity on 4E-BP1 are seen whenever mTOR is included. C, anti-C20 tuberin Ab; N, anti-N19 tuberin Ab; E, eluate. (b) Autoradiograph of a phosphatase assay. 4E-BP1 was phosphorylated in vitro using $\gamma^{32}$ P-ATP and then was included as a substrate to assess phosphatase activity of two TP53 $3^{-/-}$Tsc2 $2^{-/-}$and two TP53-/- control cell line extracts. There is no difference in the level of phosphatase activity. (c) Coomassie blue-stained gel showing successive steps in the purification of TSC1/TSC2 from brain extracts. Material bound to an anti-TSC1 affinity ( $\mathrm{H} 2 \mathrm{Ab})$ column, residual on the column after elution with peptide, the eluate, and the material obtained from an anti-TSC2 (C20) Ab column are shown in successive lanes. The location of 14-3-3 $\gamma$ is indicated by an asterisk. (d) Immunoblot analysis of Tsc1/Tsc2-binding partners. IP was performed with the indicated Ab's (Tsc2 N19, C20) followed by immunoblotting. Tsc2 row: + indicates extract from a control TP53-/- cell line; - indicates a Tsc2 $2^{-/-T P 53^{-/-}}$cell line. 


\section{Figure 5}

Reduced PI3K-Akt signaling in Tsc2 $2^{-1-T P 53^{-/-}}$and Tsc2-/- cells. (a) Immunoblot analysis of cell extracts showing reduced pAkt in Tsc2 $2^{--}$TP53 $3^{-/-}$in comparison to control TP53 ${ }^{-/-}$cells at all time points after $10 \%$ serum addition. pAkt S473, pAkt (Ser473). (b) Immunoblot analysis showing reduced $\mathrm{PAKT}$ in serum-starved $T s 1^{-1-}$ and $T s c 2^{-1-}$ TP53 $3^{-/-}$cells with and without treatment with calyculin A. (c) Autoradiography demonstrates reduced PI3K activity in Tsc2 $2^{--}$TP53 $3^{-/-}$cells in comparison with $\mathrm{TP}^{-/-}$cells, in response to PDGF. p-tyrosine, phosphotyrosine; PIP, phosphoinositide phosphate. (d) Ruffling activity, indicated by arrowheads, in response to PDGF was reduced in Tsc2 $2^{--}$TP53 $3^{-/}$cells in comparison to control $\mathrm{TP}^{-1} 3^{--}$cells or a revertant TSC2-expressing cell line. Error bars $(n=3)$ depict the SD. (e) YPH-Akt translocation is reduced in Tsc2 $2^{-/-} \mathrm{TP}_{53} 3^{--}$cells in comparison to control TP53-/cells or a revertant TSC2-expressing cell line. PDGF stimulation leads to uniform YFP staining of the plasma membrane in $T s c 2^{+/+}$ and revertant cells, but not in $T s c 2^{-/-}$cells. The staining intensity in cross-sections of the same cells is shown in the graphs at right. $\mathrm{AU}$, arbitrary units.

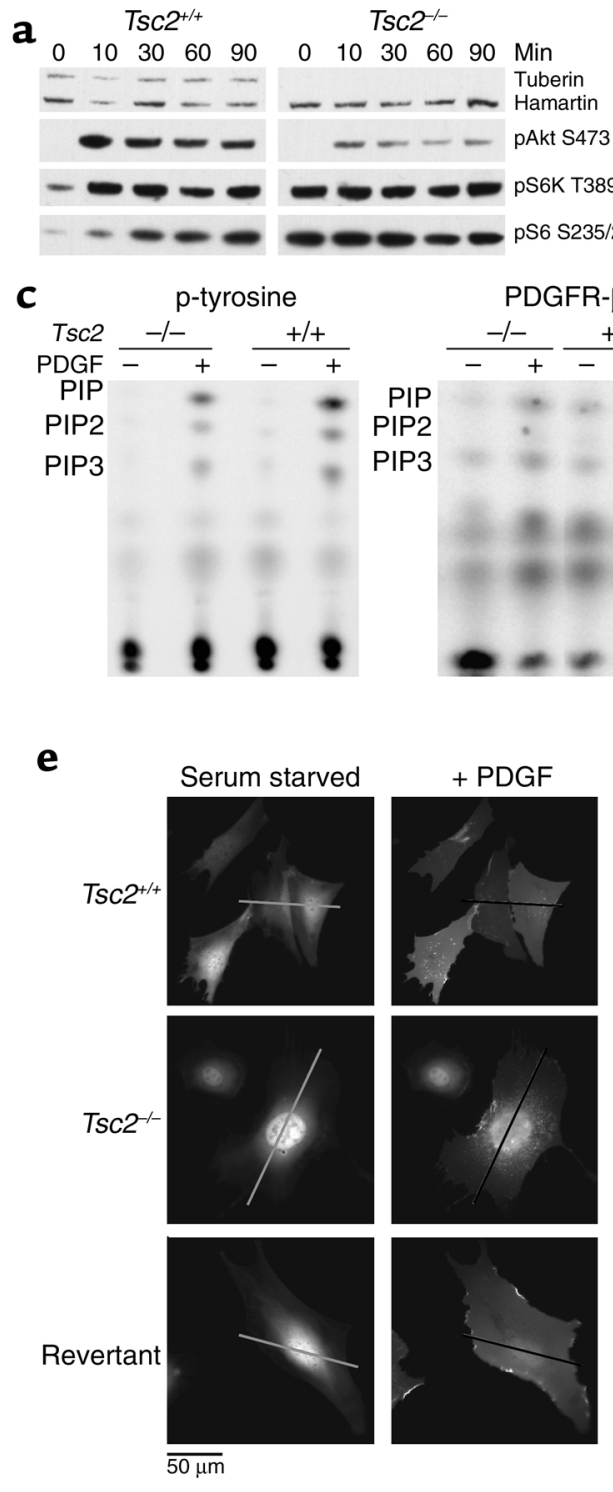

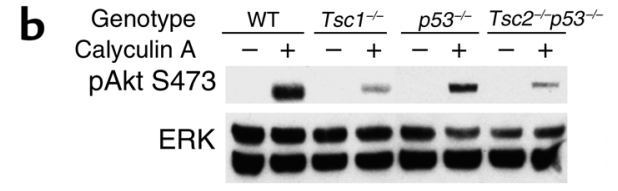
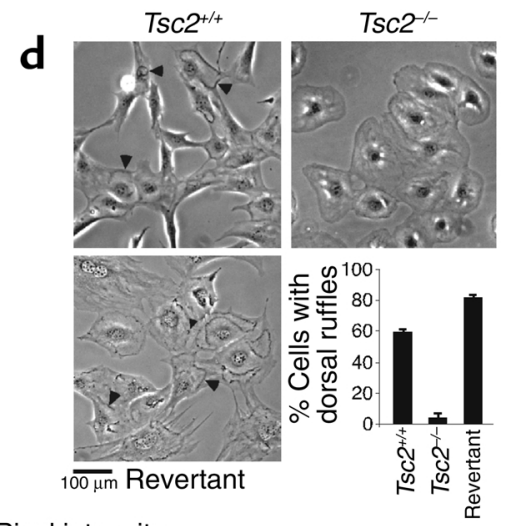

Pixel intensity of cross section

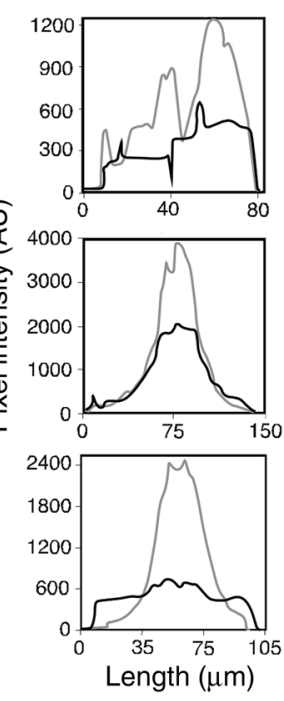

In addition, reduction in PDGFR $\beta$ expression was seen in renal cystadenomas from the $T s c 1^{+/-}$and $T s c 2^{+/-}$mice in comparison with normal renal tissue (Figure 6a). Furthermore, the extent of phosphorylation of PDGFR $\beta$ in response to PDGF treatment was greatly reduced in Tsc2-null cell lines (Figure 6b). The amount of PI3K p 85 subunit bound to the PDGFR $\beta$ receptor was also concordantly reduced, explaining the lack of an increase in $3^{\prime}$-phosphoinositide synthesis in Tsc2null cells. In the revertant cell line in which TSC2 expression was restored, pAkt generation in response to PDGF treatment was normal (Figure 6b, right). Expression of the EGFR and the p85 subunit of PI3K showed little or no difference in the TP53--Tsc2-/- compared with the $T P 53^{-/-}$cell lines (Figure $6 \mathrm{~b}$ ). The majority of these studies were performed on the $T P 53^{-/-}$cell lines of greater than P20. Observations on expression of PDGFR $\beta$ and PDGFR $\alpha$, however, and stimulation of Akt were entirely similar in these cell lines at P5 (data not shown), however.
Metabolic labeling studies performed on TP53 $3^{--}-\mathrm{TsC} 2^{-/-}$and control TP53 $3^{--}$lines demonstrated that there was reduced production of the PDGFR $\beta$ in the null cell lines, but that the half-life of PDGFR $\beta$ was similar in the two types of cells (Figure 6c). Additional evidence for the reduced function of PDGFR in cells lacking Tsc2 was the minimal growth effects of PDGF treatment with or without AG17 (PDGFR inhibitor; ref. 30) in TP53 $3^{-/-} T s c 2^{-/-}$cells (Figure $6 \mathrm{~d}$ ). In contrast, the control TP53-/- and the revertant cell lines showed the expected growth response to PDGF treatment that was inhibited by AG17. In addition, the EGF growth response was similar in both $T P 53^{-/-} T s c 2^{-/-}$and control TP53 $3^{-/}$cells, consistent with the normal levels of EGFR expression by both cell types (Figure 6d).

To confirm that the lack of PDGFR expression was the cause of reduced activation of Akt in Tsc2-null cells, we used ectopic expression of PDGFR $\beta$. TP53 $3^{--}-T_{s c 2^{-/}}$cells expressing the PDGFR $\beta$ and $\mathrm{YPH}-$ Akt by transient transfection demonstrated normal 
translocation of the reporter protein to the cell surface in response to PDGF treatment, with a uniform staining appearance (Figure 7a). Moreover, $T P 53^{-/-} \mathrm{Tsc} 2^{-/-}$ cells transfected to express PDGFR $\beta$ demonstrated enhanced activation of Akt in response to PDGF, as well as EGF, serum, and insulin (Figure 7b).

\section{Discussion}

Here we present a detailed characterization of the derivation and analysis of a series of Tsc2-null cell lines. We find that primary cultures of Tsc2-null MEFs as well as Tsc1-null MEFs (5) display more limited growth potential with early onset of senescent features and a reduced rate of spontaneous immortalization. This early senescence phenotype occurs through induction of high-level p $21^{\mathrm{CIP} 1 / \mathrm{WAF} 1}$ expression mediated by p53 (Figure 1c).

Tsc 1 and Tsc2 are known to occur in a high-affinity complex $(31,32)$. We show here that this complex persists through multiple purification steps and has a stoichiometry of 1:1 (Figure 4c). Tsc1 appears to be required to stabilize Tsc2 because Tsc2 is dramatically reduced in Tsc1-null cells (Figure 1e). Unlike recent reports $(12,13,15)$, we found that the stability and physical association of Tsc1/Tsc2 were not altered in response to growth stimulators (Figure 1e).

Building upon the initial seminal observations placing the Tsc1/Tsc2 genes in the conserved insulin receptor PI3K-Akt-S6k-signaling pathway through a genetic screen conducted in Drosophila (8-10), we showed previously that mTOR is persistently activated in Tsc1-null cells (5). Here we have extended these findings to Tsc2null cells. Analysis of growth-signaling pathways in Tsc2-null p53-null cells demonstrated that multiple independent lines had the same consistent biochemical features. In the absence of serum there is phosphorylation and activation of $\mathrm{S} 6 \mathrm{~K}$ with consequent phosphorylation of S6, its downstream substrate (Figure 2a). These findings are lacking in both control cell line

\section{Figure 6}

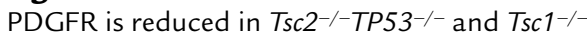
cells. (a) Immunoblot analysis of cell extracts demonstrates that both PDGFR $\beta$ and PDGFR $\alpha$ levels are reduced in both Tsc1-null and Tsc2-null cell lines compared with controls, while expression of insulin receptor $\alpha(\operatorname{IR} \alpha)$ is similar in these cells. Expression of PDGFR $\beta$ is reduced in tumor (T) extracts compared with normal kidney (NK) from both $T s c 2^{+/-}$and $T s c 1^{+/-}$mice. (b) Left top five rows, immunoblot analysis of cell extracts showing reduced amount of PDGFR $\beta$ in the $T s c 2^{-/-T P 53^{-/-}}$cell line compared with the TP53 ${ }^{-/-}$control. Left bottom three rows, analysis of PDGFR $\beta$ immunoprecipitations (IPs) showing reduced amount of PDGFR $\beta$, PPDGFR $\beta$, and bound PI3K p 85 subunit in the Tsc2 $2^{-1-T P 53^{-/-}}$ cell extracts. Right, immunoblot showing expression of PDGFR $\beta$ is restored in a TSC2-expressing revertant TP53--- cell line (pEF6/TSC2). (c) Autoradiogram showing levels of PDGFR $\beta$ in a pulse-chase experiment with $\mathrm{S}^{35}$-methionine labeling in TP53 $3^{-/-}$cells. Levels of PDGFR $\beta$ are decreased at the 0 time point in both of the $T s c 2^{-1-}$ cell lines compared with controls, but levels decline similarly during the chase. (d) BrdU incorporation experiment for serum-starved Tsc2-null, control, and revertant TP53-/- cells in response to treatment for 12 hours with 25 $\mathrm{ng} / \mathrm{ml} \mathrm{PDGF}$ with or without $25 \mu \mathrm{M}$ AG17 or 50 $\mathrm{ng} / \mathrm{ml}$ EGF and $10 \mu \mathrm{M}$ BrdU. Left, serum starvation for 1 day; right, for 3 days. Similar results were obtained using cell counting.

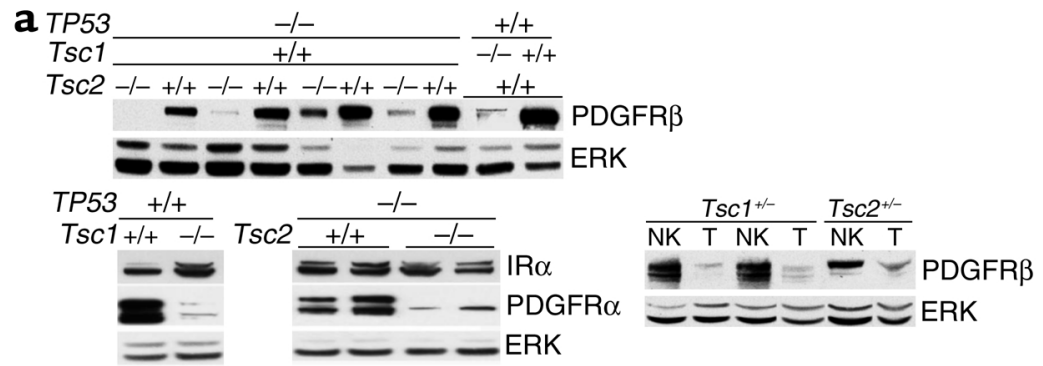

b $\underset{\text { PDG }}{\mathrm{TSF}} \frac{+/+}{+} \frac{-1-}{+}$

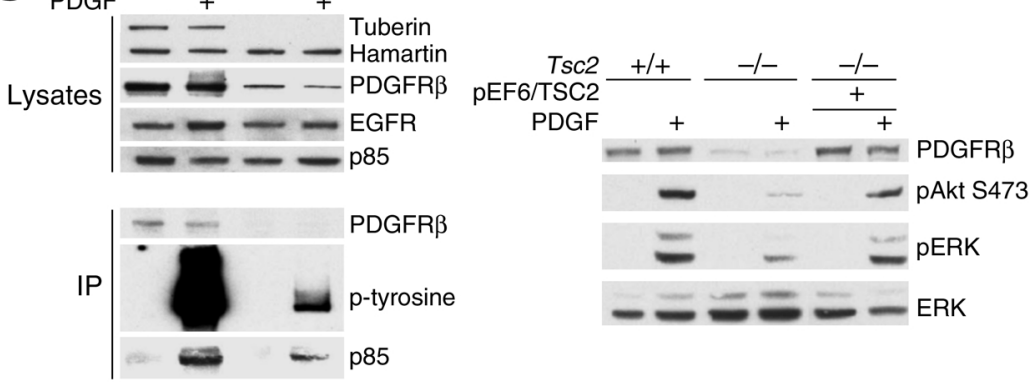

C

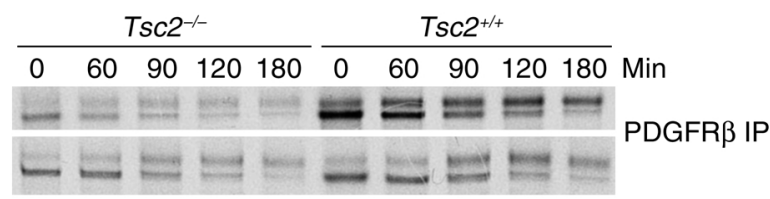

d

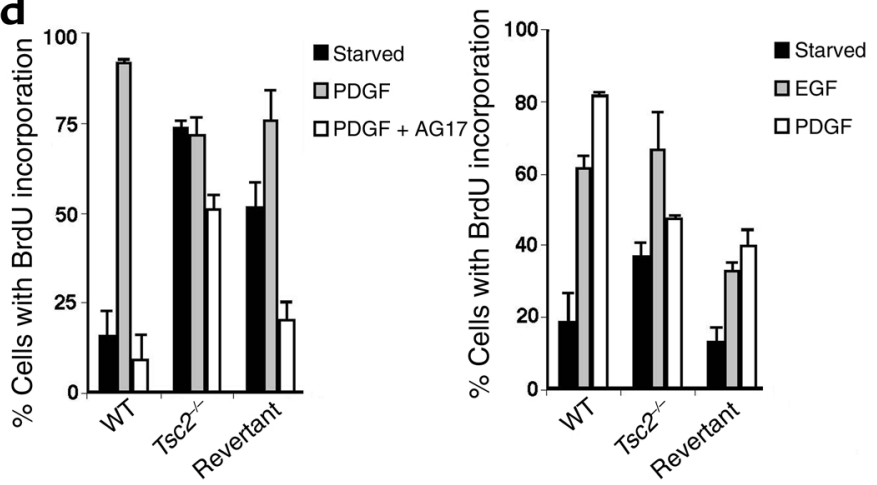


cultures from littermates and a transfected revertant cell line. High levels of pS6 are also seen in kidney tumors from both $T s c 2^{+/-}$(Figure $2 \mathrm{~b}$ ) and $T s c 1^{+/-}$mice (5). This abnormal phosphorylation signature is reverted by treatment with rapamycin and LY294002, but is not affected by treatment with wortmannin, TPCK U0126, or PD98059 (Figure 3a). These findings are consistent with activation of mTOR in these Tsc2-null cells, because LY294002 inhibits mTOR as well as PI3K (22). Despite this activation of $\mathrm{mTOR}$, the growth rate of Tsc2-null p53-null cells in 10\% serum was virtually identical to that of control p53-null cells. Continuing growth of the Tsc2-null p53-null cells was seen in the absence of serum, in contrast to control p53-null cells, however, which may relate to the tumorigenic capacity of Tsc2-null cells in vivo. This growth advantage in the absence of serum was partially reverted by rapamycin treatment (Figure 3b). These findings lend further credence to the possibility that rapamycin, which is approved for human use, may be effective in treatment of TSC-related lesions in patients. During preparation of this manuscript, several studies also implicated Tsc2 in the negative regulation of mTOR in Drosophila and transfected mammalian cells $(11,20)$. Furthermore, a mechanism for the participation of these proteins in this insulin receptor PI3K-Akt-mTORS6k-signaling pathway has also been revealed, in the form of regulation of Tsc1/Tsc2 stability and/or activity by phosphorylation at one or more sites by the Akt kinase (12-15).

In contrast to recent reports (11), we found that withdrawal of AAs from the media of Tsc2-null cells led to a significant reduction in the degree of phosphorylation of S6K and S6 (Figure 3d). In addition, 1-butanol and 2-butanol treatments, both of which reduce the level of cellular PA, also reduced the level of $66 \mathrm{~K}$ phosphorylation in Tsc2null cells (Figure 3c), consistent with regulation of mTOR activity by PA (28). These findings in aggregate are consistent with a model in which mTOR serves as an integrator of signals relating to both known signaling pathways and metabolic factors. The positioning of Tsc1/Tsc2 in this control circuit and its mode of regulation of mTOR activation is not evident. Our studies showed that mTOR does not interact physically with Tsc1/Tsc 2 in a stable manner, whereas we found that $14-3-3 \gamma$, a phospho-serine/threonine-binding protein, was associated with the complex (Figure 4c). It has been found that 14-3-3 is implicated in modulating rapamycinsensitive signaling in yeast (33). This association with $14-3-3 \gamma$ may potentially affect the interaction of Tsc1/Tsc 2 with other members of this pathway or modulate Tsc1/Tsc2 activity. We also found that Tsc1/Tsc2 did not directly affect mTOR activity in in vitro kinase assays, nor did Tsc2-null cell extracts have differential phosphatase activity on $\mathrm{p} 4 \mathrm{E}-\mathrm{BP} 1$. These observations suggest that $\mathrm{mTOR}$ is not the direct target of Tsc1/Tsc2.

We also observed that both Tsc2-null p53-null and Tsc1-null cells have a profound deficit in PI3K signaling in response to serum, PDGF, EGF, or insulin. There is a marked reduction in Akt phosphorylation in response to these stimuli. This appears to be due to reduced expression of PDGFR $\beta$ and PDGFR $\alpha$, which leads to reduced activation of PI3K, reduced 3 '-phosphoinositide synthesis, and reduced recruitment of Akt to the cell membrane where it can be phosphorylated by PDK1. The restoration of normal PDGFR $\beta$ levels, phosphorylation of Akt, and motility in the TSC2 revertant cell line suggests that this is directly related to Tsc2 expression. Since ectopic PDGFR $\beta$ expression has similar effects in restoring Akt recruitment to the membrane and activation, the reduction in PDGFR $\beta$ and PDGFR $\alpha$ in cells lacking Tsc 2 or
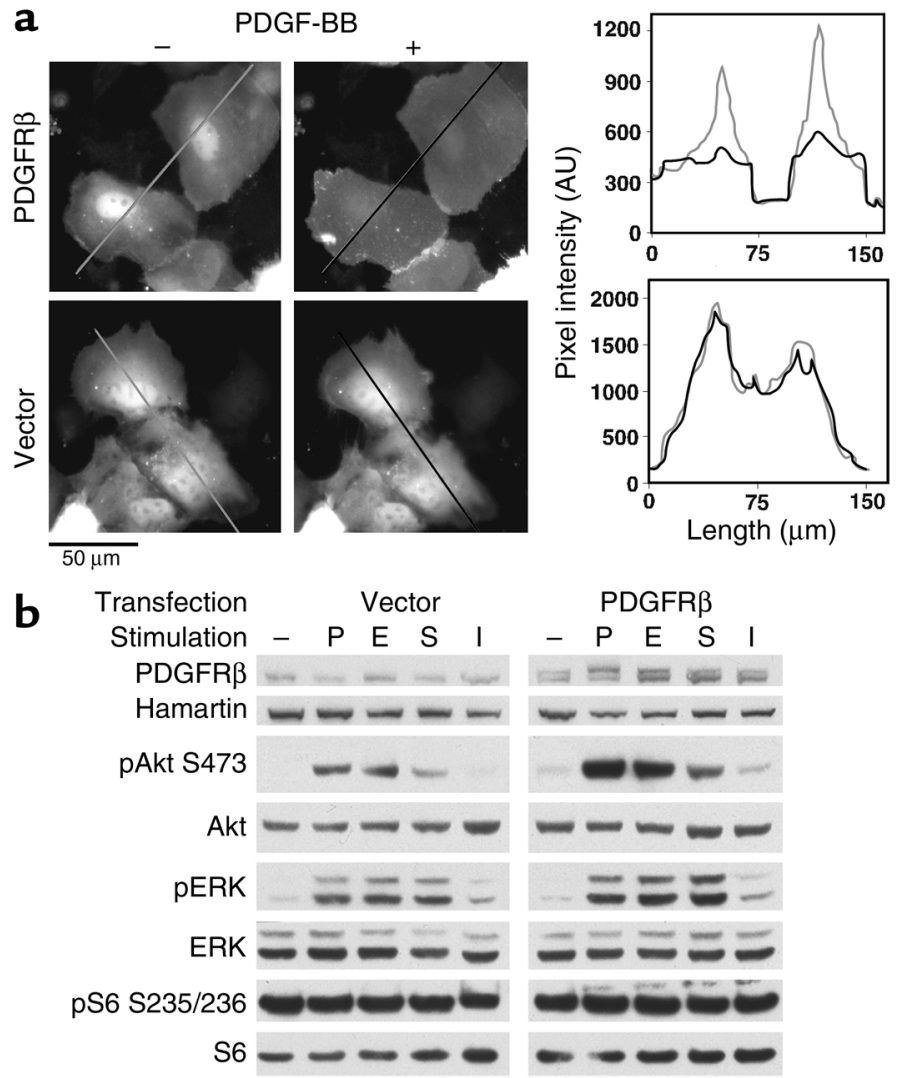

\section{Figure 7}

Correction of Akt signaling in Tsc2-/-TP53-/- cells by PDGFR $\beta$ transfection. (a) YPH-Akt translocation. Tsc2 $2^{-/-}$TP53 $3^{-/-}$cells were cotransfected with $\mathrm{YPH}$ Akt and PDGFR $\beta$ or an empty vector and were serum starved overnight before PDGF addition. The left and right panels are fluorescent images of the cells before and 4 minutes after PDGF addition, respectively. PDGF stimulation leads to uniform YFP staining of the plasma membrane in cells transfected with the PDGFR $\beta$, but not in cells transfected with empty vector. The staining intensity in cross-sections of the same cells is shown in the graphs at right. (b) Recovery of Akt activation. Immunoblot analysis of $T s c 2^{-/-}$TP53 $3^{-/-}$cells transfected with empty vector (left) or PDGFR $\beta$ (right) that were serum starved and then stimulated with $50 \mathrm{ng} / \mathrm{ml}$ PDGF-BB (P), $100 \mathrm{ng} / \mathrm{ml} \mathrm{EGF} \mathrm{(E),}$ $10 \%$ serum (S), or $0.1 \mu \mathrm{M}$ insulin (I). Note the increase in the Akt phosphorylation in the PDGFR-transfected cells in response to all stimuli. 
Tsc1 is the mechanism of this defect in PI3K-Akt signaling. Reduced expression of PDGFR $\beta$ is also seen in the renal cystadenomas that occur in $\mathrm{Tsc}^{+/-}$and $\mathrm{Tsc}^{+/-}$mice, and studies in the null cell lines indicate that reduced synthesis of PDGFR $\beta$ accounts for the reduced levels of expression of PDGFR $\beta$. Although the majority of these observations were made on Tsc2-null cells that were also p53 null, similar findings were seen in Tsc1-null cells, the single NIH3T3 Tsc2-null line that we developed (data not shown), and on tumors from the $T s c 2^{+/-}$and $T s c 2^{+/-}$mice, indicating that $\mathrm{p} 53$ status is very likely not critical for this defect in PDGFR-PI3K-Akt signaling.

The precise mechanism by which loss of Tsc2 or Tsc 1 leads to reduced PDGFR synthesis is uncertain, though previous studies have indicated regulation of PDGFR synthesis by a variety of oncogenes (34). It is striking that ectopic expression of PDGFR $\beta$ enhanced Akt activation in the null cells in response to several stimuli (Figure 7b), suggesting that PDGFR $\beta$ has a role in facilitating intracellular signaling even in the absence of binding to its ligand PDGF.

This paradoxical defective signaling through the PDGFRs, PI3K, and Akt, along with activation of mTOR, appear likely to help explain why TSC-related hamartomas rarely become malignant $(1,2)$ and the TSC genes are so rarely involved in the common adult malignancies. This is in contrast to PTEN, an upstream negative regulator in this pathway, whose inactivation leads to activation of both mTOR and Akt and which is very commonly involved in many malignancies (35). Thus, inhibition of PDGFR signaling may be considered as a potential strategy to treat patients with various malignant tumors.

\section{Acknowledgments}

We thank Richard Lamb and William Sellers for helpful discussions; Victoria Walker, Sandy Dabora, and Penny Roberts for assistance; and William Watts for support. This work was supported by NIH grants NS-31535, GM-54389, HL-07680, and NS-41498; the Tuberous Sclerosis Alliance; the March of Dimes; and the Rothberg Courage Fund.

1. Cheadle, J.P., Reeve, M.P., Sampson, J.R., and Kwiatkowski, D.J. 2000. Molecular genetic advances in tuberous sclerosis. Hum. Genet. 107:97-114.

2. Gomez, M., Sampson, J., and Whittemore, V. 1999. The tuberous sclerosis complex. Oxford University Press. Oxford, United Kingdom. 340 pp.

3. Roach, E.S., Gomez, M.R., and Northrup, H. 1998. Tuberous sclerosis complex consensus conference: revised clinical diagnostic criteria. J. Child Neurol. 13:624-628.

4. Onda, H., Lueck, A., Marks, P.W., Warren, H.B., and Kwiatkowski, D.J. 1999. Tsc2(+/-) mice develop tumors in multiple sites that express gelsolin and are influenced by genetic background. J. Clin. Invest. 104:687-695.

5. Kwiatkowski, D.J., et al. 2002. A mouse model of TSC1 reveals sexdependent lethality from liver hemangiomas, and up-regulation of p70S6 kinase activity in Tsc1 null cells. Hum. Mol. Genet. 11:525-534.

6. Kobayashi, T., et al. 2001. A germ-line Tsc1 mutation causes tumor development and embryonic lethality that are similar, but not identical to, those caused by Tsc2 mutation in mice. Proc. Natl. Acad. Sci. U. S. A. 98:8762-8767.

7. Kobayashi, T., et al. 1999. Renal carcinogenesis, hepatic hemangiomatosis, and embryonic lethality caused by a germ-line Tsc2 mutation in mice. Cancer Res. 59:1206-1211.
8. Tapon, N., Ito, N., Dickson, B.J., Treisman, J.E., and Hariharan, I.K. 2001. The Drosophila tuberous sclerosis complex gene homologs restrict cell growth and cell proliferation. Cell. 105:345-355.

9. Potter, C.J., Huang, H., and Xu, T. 2001. Drosophila TSC1 functions with TSC2 to antagonize insulin signaling in regulating cell growth, cell proliferation, and organ size. Cell. 105:357-368.

10. Gao, X., and Pan, D. 2001. TSC1 and TSC2 tumor suppressors antagonize insulin signaling in cell growth. Genes Dev. 15:1383-1392.

11. Gao, X., et al. 2002. Tsc tumour suppressor proteins antagonize aminoacid-TOR signalling. Nat. Cell. Biol. 4:699-704.

12. Potter, C.J., Pedraza, L.G., and Xu, T. 2002. Akt regulates growth by directly phosphorylating Tsc2. Nat. Cell. Biol. 4:658-665.

13. Dan, H.C., et al. 2002. PI3K/AKT pathway regulates TSC tumor suppressor complex by phosphorylation of tuberin. J. Biol. Chem. 277:35364-35370.

14. Manning, B.D., Tee, A.R., Logsdon, M.N., Blenis, J., and Cantley, L.C. 2002. Identification of the tuberous sclerosis complex-2 tumor suppressor gene product tuberin as a target of the phosphoinositide 3-kinase/akt pathway. Mol. Cell. 10:151-162.

15. Inoki, K., Li, Y., Zhu, T., Wu, J., and Guan, K.L. 2002. TSC2 is phosphorylated and inhibited by Akt and suppresses mTOR signalling. Nat. Cell. Biol. 4:648-657.

16. Donehower, L.A., et al. 1992. Mice deficient for $\mathrm{p} 53$ are developmentally normal but susceptible to spontaneous tumours. Nature. 356:215-221.

17. Peterson, R.T., Desai, B.N., Hardwick, J.S., and Schreiber, S.L. 1999. Protein phosphatase $2 \mathrm{~A}$ interacts with the $70-\mathrm{kDa}$ S6 kinase and is activated by inhibition of FKBP12-rapamycin associated protein. Proc. Natl. Acad. Sci. U. S. A. 96:4438-4442.

18. Tolias, K.F., Cantley, L.C., and Carpenter, C.L. 1995. Rho family GTPases bind to phosphoinositide kinases. J. Biol. Chem. 270:17656-17659.

19. Soucek, T., Yeung, R.S., and Hengstschlager, M. 1998. Inactivation of the cyclin-dependent kinase inhibitor p27 upon loss of the tuberous sclerosis complex gene-2. Proc. Natl. Acad. Sci. U. S. A. 95:15653-15658.

20. Goncharova, E.A., et al. 2002. Tuberin regulates p70 S6 kinase activation and ribosomal protein S6 phosphorylation: a role for the TSC2 tumor suppressor gene in pulmonary lymphangioleiomyomatosis (LAM). J. Biol. Chem. 277:30958-30967.

21. Brown, E.J., et al. 1994. A mammalian protein targeted by G1-arresting rapamycin-receptor complex. Nature. 369:756-758.

22. Brunn, G.J., et al. 1996. Direct inhibition of the signaling functions of the mammalian target of rapamycin by the phosphoinositide 3-kinase inhibitors, wortmannin and LY294002. EMBOJ. 15:5256-5267.

23. Arcaro, A., and Wymann, M.P. 1993. Wortmannin is a potent phosphatidylinositol 3-kinase inhibitor: the role of phosphatidylinositol 3,4,5-trisphosphate in neutrophil responses. Biochem. J. 296:297-301.

24. Ballif, B.A., Shimamura, A., Pae, E., and Blenis, J. 2001. Disruption of 3-phosphoinositide-dependent kinase 1 (PDK1) signaling by the antitumorigenic and anti-proliferative agent n-alpha-tosyl-l-phenylalanyl chloromethyl ketone. J. Biol. Chem. 276:12466-12475.

25. Duncia, J.V., et al. 1998. MEK inhibitors: the chemistry and biological activity of U0126, its analogs, and cyclization products. Bioorg. Med. Chem. Lett. 8:2839-2844.

26. Alessi, D.R., Cuenda, A., Cohen, P., Dudley, D.T., and Saltiel, A.R. 1995. PD 098059 is a specific inhibitor of the activation of mitogen-activated protein kinase kinase in vitro and in vivo. J. Biol. Chem. 270:27489-27494.

27. Ishihara, H., et al. 1989. Calyculin A and okadaic acid: inhibitors of protein phosphatase activity. Biochem. Biophys. Res. Commun. 159:871-877.

28. Fang, Y., Vilella-Bach, M., Bachmann, R., Flanigan, A., and Chen, J. 2001. Phosphatidic acid-mediated mitogenic activation of mTOR signaling. Science. 294:1942-1945.

29. Hara, K., et al. 1998. Amino acid sufficiency and mTOR regulate p70 S6 kinase and eIF-4E BP1 through a common effector mechanism. J. Biol. Chem. 273:14484-14494.

30. Bilder, G.E., et al. 1991. Tyrphostins inhibit PDGF-induced DNA synthesis and associated early events in smooth muscle cells. Am. J. Physiol. 260:C721-C730.

31. van Slegtenhorst, M., et al. 1998. Interaction between hamartin and tuberin, the TSC1 and TSC2 gene products. Hum. Mol. Genet. 7:1053-1058.

32. Plank, T.L., Yeung, R.S., and Henske, E.P. 1998. Hamartin, the product of the tuberous sclerosis 1 (TSC1) gene, interacts with tuberin and appears to be localized to cytoplasmic vesicles. Cancer Res. 58:4766-4770.

33. Bertram, P.G., Zeng, C., Thorson, J., Shaw, A.S., and Zheng, X.F.S. 1998. The 14-3-3 proteins positively regulate rapamycin-sensitive signaling. Curr. Biol. 8:1259-1267.

34. Paasinen-Sohns, A., and Holtta, E. 1997. Cells transformed by ODC, c-Ha-ras and v-src exhibit MAP kinase/Erk-independent constitutive phosphorylation of Sos, Raf and c-Jun activation domain, and reduced PDGF receptor expression. Oncogene. 15:1953-1966.

35. Fernandez, M., and Eng, C. 2002. The expanding role of PTEN in neoplasia: a molecule for all seasons? Clin. Cancer Res. 8:1695-1698. 